\title{
Micellar Catalysis on 1,10-Phenanthroline Promoted Chromic Acid Oxidation of Propanol in Aqueous Media
}

\author{
Sumanta K. Ghosh, Rumpa Saha, Kakali Mukherjee, Aniruddha Ghosh, \\ Subhendu Sekhar Bhattacharyya, and Bidyut Saha* \\ Catalysis Laboratory, Department of Chemistry, The University of Burdwan, Golapbag, Burdwan, \\ Pin 731104,WB, India. *E-mail: b_saha31@rediffmail.com \\ (Received December 29, 2011; Accepted December 30, 2011)
}

Key words: Propanol, Chromic acid, Phenanthroline, Micellar catalyst

The catalysis of reaction by organized media is of increasing interest. ${ }^{1-5}$ In these systems, aggregates act as nano or microreactors, compartmentalizing and concentrating or diluting reagents and thereby altering the observed rate of chemical reactions. ${ }^{6}$ Surfactant systems are well known for their high capacity for reactant solubilization in spite of their type: organic, inorganic, polar and nonpolar. ${ }^{7}$ The green chemistry aspect of using water as environmentally and user-friendly solvent for chemical reactions has sparked much interest with an impressive number. A micellar system appears to be homogeneous since these aggregates are of colloidal size; however in reality the absorbed reactants are in a microheterogeneous two phase system. ${ }^{8}$ The catalytic efficiency will be governed by the affinity of the reactivity of the bound reagent molecules. Oxidation is a key reaction for different organic synthesis. ${ }^{9}$ Chromic acid is a widely used oxidizing agent. ${ }^{10} 1$, 10-phenanthroline is well known to act as a promoter for $\mathrm{Cr}(\mathrm{VI})$ oxidation of organic substances. ${ }^{11}$ Bipyridine (bpy) and picolinic acid are also used as good promoter for chromic acid oxidation but here the work is only concentrated on the promoter phenanthroline. Under the kinetically reaction conditions $[\text { propanol }]_{\mathrm{T}}>[\mathrm{Cr}(\mathrm{VI})]_{\mathrm{T}}$ (subscript $\mathrm{T}$ stands for the total concentration), and the alcohol upon oxidation yields propannal which was confirmed by the production of 2,4-dinitrophenylhydrazone derivatives. ${ }^{12}$ The overall stoichiometry of the reaction may be represented as:

$$
\begin{array}{rl}
3 \mathrm{CH}_{3} \mathrm{CH}_{2} \mathrm{CH}_{2} \mathrm{OH}+ & 2 \mathrm{HCrO}_{4}^{-}+8 \mathrm{H}^{+} \rightarrow \\
2 & \mathrm{Cr}(\mathrm{III})+3 \mathrm{CH}_{3} \mathrm{CH}_{2} \mathrm{CHO}+8 \mathrm{H}_{2} \mathrm{O}
\end{array}
$$

The rate of disappearance of $\mathrm{Cr}(\mathrm{VI})$ shows the first order kinetics on $[\mathrm{Cr}(\mathrm{VI})]_{\mathrm{T}}$. The pseudo first-order rate constants $\left(k_{\mathrm{obs}}\right)$ have been determined from plots of $\ln [\mathrm{Cr}(\mathrm{VI})]_{\mathrm{t}} \mathrm{vs}$. time $(\mathrm{t})$ by using the equation $\ln [\mathrm{Cr}(\mathrm{VI})]_{\mathrm{t}}=$

$\ln [\mathrm{Cr}(\mathrm{VI})]_{0}-k \mathrm{t}$. The formation of a $\mathrm{Cr}(\mathrm{III})-$ phen complex (identified spectroscopically) indicates that phen undergoes complexation with the higher oxidation states (which are labile) of chromium. Due to the inertness of $\mathrm{Cr}$ (III), phen does not bind the $\mathrm{Cr}$ (III) produced after the completion of $\mathrm{Cr}(\mathrm{VI})$. Here it is quite reasonable to accept that $\mathrm{Cr}(\mathrm{VI})$-phen complex formed at the pre-equilibrium step which is the active oxidant for this reaction. The observed rate law and the cyclic transition state reduction of $\mathrm{Cr}(\mathrm{VI})$ to $\mathrm{Cr}(\mathrm{IV})$ occur through $\mathrm{H}+$ transfer (rate determining step) is supported by our previous work on the oxidation of propanol to propanal. ${ }^{12} \mathrm{Cr}(\mathrm{VI})$ is further reduced to $\mathrm{Cr}$ (III) (Not shown the manuscript).

Scheme 2 is drawn on the basis that the reaction follows first order dependency on $[\text { propanol }]_{\mathrm{T}},[\mathrm{Cr}(\mathrm{VI})]_{\mathrm{T}}$, $[\text { Phen }]_{\mathrm{T}}$ and $\left[\mathrm{H}^{+}\right]$(Not shown in the paper).

The colours of the final solutions in the absence of promoter and in the presence of the promoter are far different indicating different types of species. The observed final colour of the solution in the absence of phen under the experimental condition is pale blue $\left(\lambda_{\max }=413 \mathrm{~nm}\right.$ and 586 $\mathrm{nm})$ and the corresponding transitions ${ }^{10 \mathrm{c}}$ are $586 \mathrm{~nm}$ for ${ }^{4} \mathrm{~A}_{2 \mathrm{~g}}(\mathrm{~F}) \rightarrow{ }^{4} \mathrm{~T}_{2 \mathrm{~g}}(\mathrm{~F})$ and $413 \mathrm{~nm}$ for ${ }^{4} \mathrm{~A}_{2 \mathrm{~g}}(\mathrm{~F}) \rightarrow{ }^{4} \mathrm{~T}_{1 \mathrm{~g}}(\mathrm{~F})$ of $\mathrm{Cr}(\mathrm{III})$ species while the final colour of the solution of phen-promoted reaction under the same kinetic condition is pale

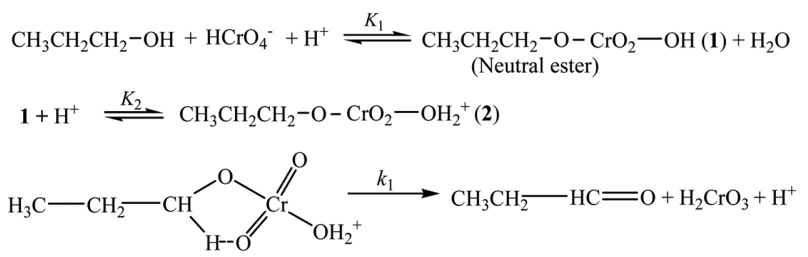

(2)

Scheme 1. Cr(VI) oxidation of propanol in the absence of 1, 10phenanthroline. 


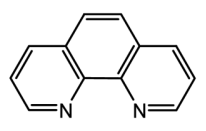<smiles>[Y6]=CC=Cc1ccc2ccc3ccc[nH+]c3c2n1</smiles>

$\mathrm{HCrO}_{4}^{-}+2 \mathrm{H}^{+}+$<smiles></smiles>
$\mathrm{K}_{3}$

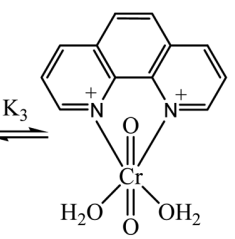<smiles>O=C(O)[n+]1cccc2ccc3cccnc3c21</smiles>
$\left.\right|_{\mathrm{CH}_{2} \mathrm{CH}_{3}} ^{\mathrm{OH}}$

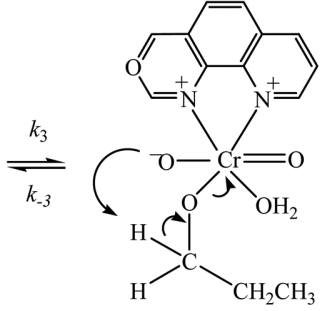
$\downarrow k_{4}$

$\mathrm{CH}_{3} \mathrm{CH}_{2} \mathrm{CH}=\mathrm{O}+\mathrm{Cr}(\mathrm{IV})$-phen

Scheme 2. Cr(VI) oxidation of propanol in the presence of 1,10 phenanthroline.

violet $\left[\lambda_{\max }=546 \mathrm{~nm}\right.$, for ${ }^{4} \mathrm{~A}_{2 \mathrm{~g}}(\mathrm{~F}) \rightarrow{ }^{4} \mathrm{~T}_{2 \mathrm{~g}}(\mathrm{~F})$ of $\mathrm{Cr}(\mathrm{III})$ species]. The spectra of the final solution without promoter reaction and pure chromic sulphate solution in aqueous sulphuric acid media are identical. This is consistent with the final $\mathrm{Cr}$ (III) species which is simply $\mathrm{Cr}$ (III)-species for the unpromoted reaction while for the promoted reaction (phen); the final $\mathrm{Cr}(\mathrm{III})$-species is a different species, which is $\mathrm{Cr}(\mathrm{III})$-promoter complex. In the phen promoted

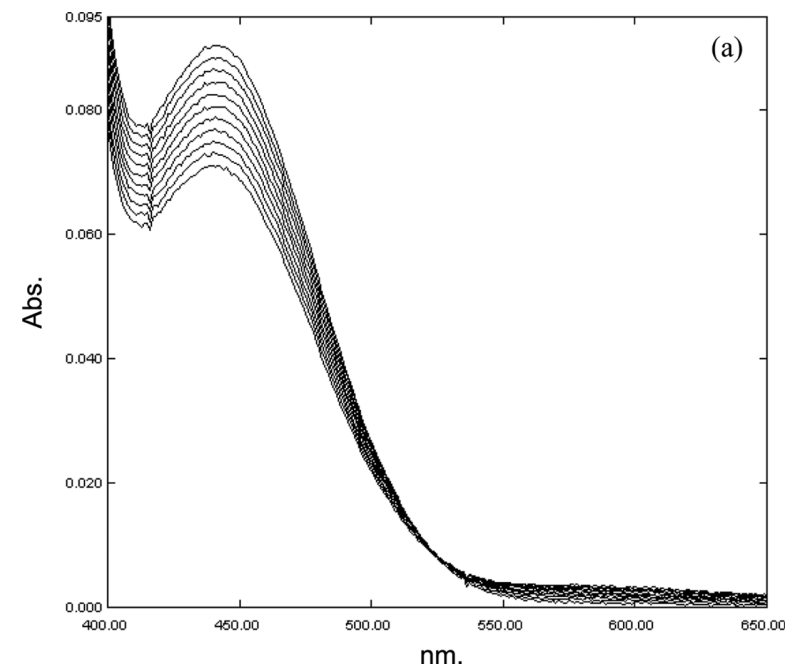

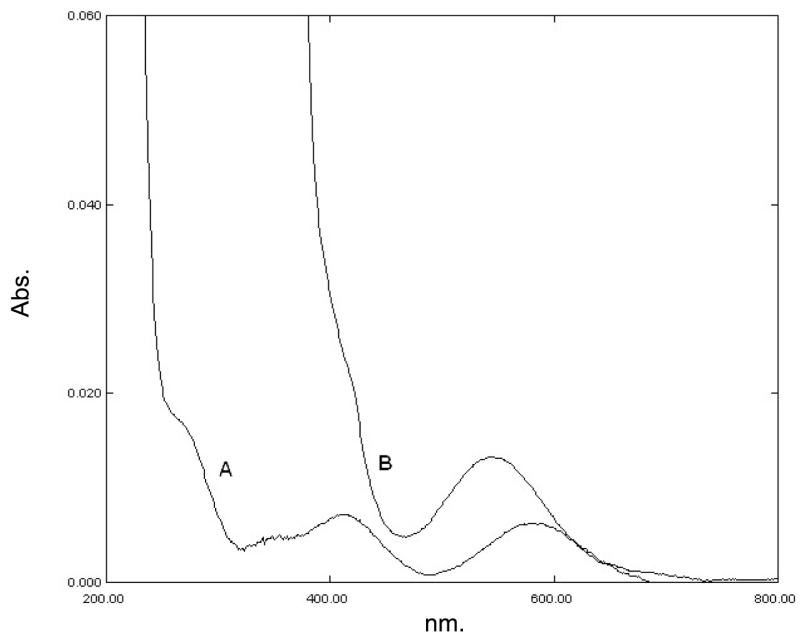

Fig. 1. Absorption spectrum (after completion of reaction) of (A) unpromoted reaction mixture: [propanol $]_{\mathrm{T}}=75 \times 10^{-4} \mathrm{~mol} \mathrm{dm}^{-3}$, $[\mathrm{Cr}(\mathrm{VI})]_{\mathrm{T}}=5 \times 10^{-4} \mathrm{~mol} \mathrm{dm}^{-3},\left[\mathrm{H}_{2} \mathrm{SO}_{4}\right]_{\mathrm{T}}=0.5 \mathrm{~mol} \mathrm{dm}^{-3}$ (The spectrum of the chromic sulfate is identical with this under the experimental condition). (B) Promoted reaction mixture [propanol $]_{\mathrm{T}}=$ $75 \times 10^{-4} \mathrm{~mol} \mathrm{dm}^{-3},[\mathrm{Cr}(\mathrm{VI})]_{\mathrm{T}}=5 \times 10^{-4} \mathrm{~mol} \mathrm{dm}^{-3},\left[\mathrm{H}_{2} \mathrm{SO}_{4}\right]_{\mathrm{T}}=0.5 \mathrm{~mol}$ $\mathrm{dm}^{-3}$. [phen $]_{\mathrm{T}}=50 \times 10^{-4} \mathrm{~mol} \mathrm{dm}{ }^{-3}$.

reaction path, there is a hypsochromic (blue) shift (Fig. 1) for the peak due to the transition ${ }^{4} \mathrm{~A}_{2 \mathrm{~g}}(\mathrm{~F}) \rightarrow{ }^{4} \mathrm{~T}_{2 \mathrm{~g}}(\mathrm{~F})$ compared to the final solution without promoter path. Phenanthroline contain two strong field donor site i.e., heteroatomic shift. The peak due to the transition ${ }^{4} \mathrm{~A}_{2 g}(\mathrm{~F}) \rightarrow{ }^{4} \mathrm{~T}_{2 \mathrm{~g}}(\mathrm{~F})$ simply explains the charge-transfer band in the $\mathrm{Cr}$ (III)-promoter complex (Fig. 1). The band around $265 \mathrm{~nm}$ in $\mathrm{Cr}$ (III)-aqueous species arises as a shoulder due to ${ }^{4} \mathrm{~A}_{2 \mathrm{~g}}(\mathrm{~F}) \rightarrow{ }^{4} \mathrm{~T}_{1 \mathrm{~g}}(\mathrm{P})$ transition and it is of high energy charge-transfer band i.e., in ultraviolet region. ${ }^{10 \mathrm{c}} \mathrm{In} \mathrm{Cr}(\mathrm{III})$-promoter complex, the

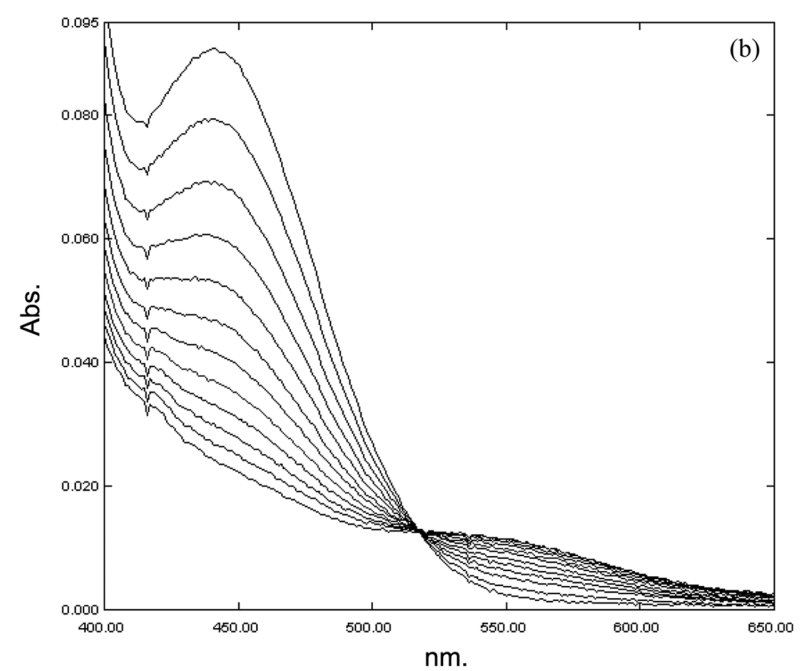

Fig. 2. (a) Scanned absorption spectra of the reaction mixture at regular time intervals $(15 \mathrm{~min})$. [propanol $]_{\mathrm{T}}=75 \times 10^{-4} \mathrm{~mol} \mathrm{dm}{ }^{-3},[\mathrm{Cr}(\mathrm{VI})]_{\mathrm{T}}$ $=5 \times 10^{-4} \mathrm{~mol} \mathrm{dm}^{-3},\left[\mathrm{H}_{2} \mathrm{SO}_{4}\right]_{\mathrm{T}}=0.5 \mathrm{~mol} \mathrm{dm}^{-3}$. (b) Scanned absorption spectra of the reaction mixture at regular time intervals (4 min). [propanol $]_{\mathrm{T}}=75 \times 10^{-4} \mathrm{~mol} \mathrm{dm}^{-3},[\mathrm{Cr}(\mathrm{VI})]_{\mathrm{T}}=5 \times 10^{-4} \mathrm{~mol} \mathrm{dm}^{-3},\left[\mathrm{H}_{2} \mathrm{SO}_{4}\right]_{\mathrm{T}}=0.5 \mathrm{~mol} \mathrm{dm}{ }^{-3}$. [phen $]_{\mathrm{T}}=50 \times 10^{-4} \mathrm{~mol} \mathrm{dm}^{-3}$. 
appearance of the charge-transfer band at much lower energy i.e., in visible range for the proposed $\mathrm{Cr}(\mathrm{III})$-promoter complex is quite reasonable because of the favoured metal to ligand charge-transfer. The vacant $\pi^{*}$ M.O. of the phen switches the metal to ligand electron-transfer. The rate of the in phen promoted path is excessively enhanced by the charge-transfer band (metal to ligand) at lower energy. Wavelength of this corresponding charge-transfer band is shifted to a lower value than the wave legth of the corresponding band in unpromoted path.

The scanned spectrum indicates the gradual disappearance of $\mathrm{Cr}(\mathrm{VI})$ species and appearance of $\mathrm{Cr}(\mathrm{III})$ with an isobestic point at $\lambda=524 \mathrm{~nm}$ for the unpromoted (Fig. 2a) and phen promoted (isobestic point at $\lambda=518 \mathrm{~nm}$ ) (Fig. 2b) reaction.

The following scanned spectrum is observed for SDS (in presence of promoter phen) catalyzed chromic acid oxidation of propanol with an isobestic point at $\lambda=520$

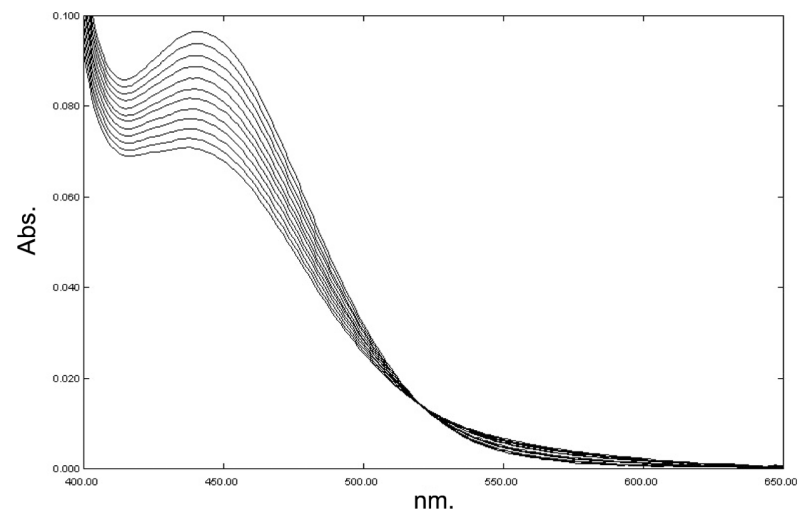

Fig. 3. Scanned absorption spectra of the reaction mixture at regular time intervals $(2 \mathrm{~min})$. [propanol $]_{\mathrm{T}}=75 \times 10^{-4} \mathrm{~mol} \mathrm{dm}^{-3}$, $[\mathrm{Cr}(\mathrm{VI})]_{\mathrm{T}}=5 \times 10^{-4} \mathrm{~mol} \mathrm{dm}^{3},\left[\mathrm{H}_{2} \mathrm{SO}_{4}\right]_{\mathrm{T}}=0.5 \mathrm{~mol} \mathrm{dm}^{-3} .[\mathrm{SDS}]_{\mathrm{T}}$ $=0.01 \mathrm{~mol} \mathrm{dm}^{-3}$. [phen $]_{\mathrm{T}}=50 \times 10^{-4} \mathrm{~mol} \mathrm{dm}{ }^{-3}$.

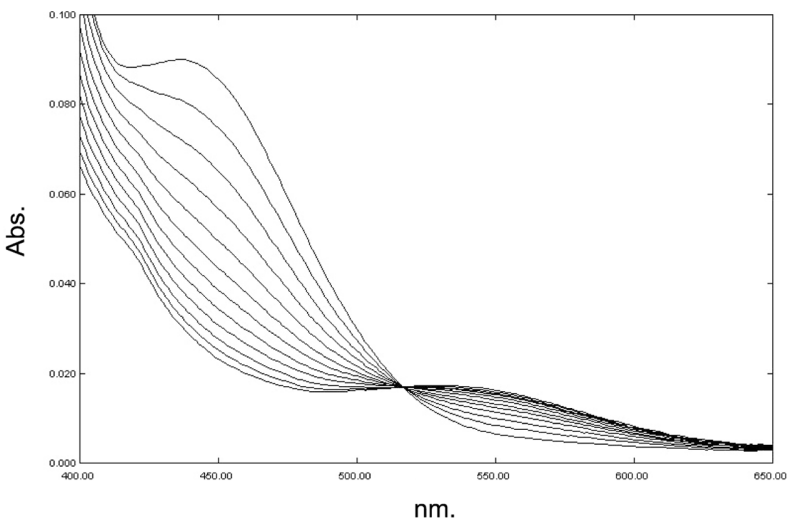

Fig. 4. Scanned absorption spectra of the reaction mixture at regular time intervals (3 min). [propanol $]_{\mathrm{T}}=75 \times 10^{-4} \mathrm{~mol} \mathrm{dm}^{-3},[\mathrm{Cr}(\mathrm{VI})]_{\mathrm{T}}$ $=5 \times 10^{-4} \mathrm{~mol} \mathrm{dm}^{-3},\left[\mathrm{H}_{2} \mathrm{SO}_{4}\right]_{\mathrm{T}}=0.5 \mathrm{~mol} \mathrm{dm}^{-3} .[\mathrm{TX}-100]_{\mathrm{T}}=0.05$ $\mathrm{mol} \mathrm{dm}{ }^{-3}$. [phen $]_{\mathrm{T}}=50 \times 10^{-4} \mathrm{~mol} \mathrm{dm}^{-3}$.

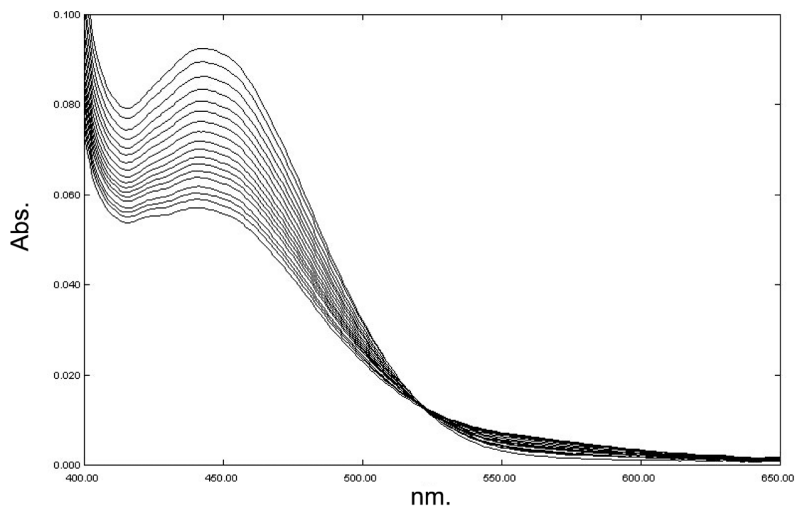

Fig. 5. Scanned absorption spectra of the reaction mixture at regular time intervals $(2 \mathrm{~min})$. $[\text { propanol }]_{\mathrm{T}}=75 \times 10^{-4} \mathrm{~mol} \mathrm{dm}^{-3},[\mathrm{Cr}(\mathrm{VI})]_{\mathrm{T}}$ $=5 \times 10^{-4} \mathrm{~mol} \mathrm{dm}^{-3},\left[\mathrm{H}_{2} \mathrm{SO}_{4}\right]_{\mathrm{T}}=0.5 \mathrm{~mol} \mathrm{dm}^{-3} \cdot[\mathrm{CPC}]_{\mathrm{T}}=0.002$ $\mathrm{mol} \mathrm{dm}{ }^{-3}$, [phen $]_{\mathrm{T}}=50 \times 10^{-4} \mathrm{~mol} \mathrm{dm}^{-3}$.

nm (Fig. 3).

Triton X-100 with promoter (phen) gives the similar type of scanned spectrum for the disappearance of $\mathrm{Cr}(\mathrm{VI})$ species and appearance of $\mathrm{Cr}(\mathrm{III})$ species with an isobestic point at $\lambda=516 \mathrm{~nm}$ (Fig. 4).

CPC with promoter (phen) gives the similar type of scanned spectrum for the disappearance of $\mathrm{Cr}(\mathrm{VI})$ species and appearance of $\mathrm{Cr}(\mathrm{III})$ species with an isobestic point at $\lambda=522 \mathrm{~nm}$ (Fig. 5).

In unpromoted path (Scheme 1) the partitioning of neutral ester in all kind of micellar phase is possible. Partitioning of proton is maximum in SDS due to electrostatic attraction less in CPC due to electrostatic repulsion. Rate is maximum in SDS, minimum in CPC and TX-100 has effect in between them (Table 1).

The active oxidant participate is $\mathrm{Cr}(\mathrm{VI})$-phen complex (supported by Fig. 6) reacts with the substrate (Scheme 2)

Table 1. Reaction completion time in presence and absence of micellar catalyst

\begin{tabular}{|c|c|c|}
\hline \multicolumn{2}{|c|}{ Micellar catalyst $\left[\mathrm{mol} \mathrm{dm}^{-3}\right]$} & $\mathrm{T}_{\text {com }}[\mathrm{hrs}]$ \\
\hline \multicolumn{2}{|c|}{ None } & 33 \\
\hline \multirow{4}{*}{ SDS } & $1 \times 10^{-2}$ & 11.03 \\
\hline & $2 \times 10^{-2}$ & 8.84 \\
\hline & $3 \times 10^{-2}$ & 6.33 \\
\hline & $4 \times 10^{-2}$ & 5.18 \\
\hline \multirow{4}{*}{ TX-100 } & $2 \times 10^{-2}$ & 39.46 \\
\hline & $3 \times 10^{-2}$ & 26.65 \\
\hline & $4 \times 10^{-2}$ & 19.57 \\
\hline & $5 \times 10^{-2}$ & 18.62 \\
\hline \multirow{3}{*}{$\mathrm{CPC}$} & $2 \times 10^{-2}$ & 43.42 \\
\hline & $6 \times 10^{-2}$ & 52.9 \\
\hline & $8 \times 10^{-2}$ & 158 \\
\hline
\end{tabular}

$[\mathrm{Cr}(\mathrm{VI})]_{\mathrm{T}}=5 \times 10^{-4} \mathrm{~mol} \mathrm{dm}^{-3},\left[\mathrm{H}_{2} \mathrm{SO}_{4}\right]_{\mathrm{T}}=0.5 \mathrm{~mol} \mathrm{dm}^{-3}$, [propanol $]_{\mathrm{T}}$ $=75 \times 10^{-4} \mathrm{~mol} \mathrm{dm}^{-3}, \mathrm{Temp}=30^{\circ} \mathrm{C}$. 


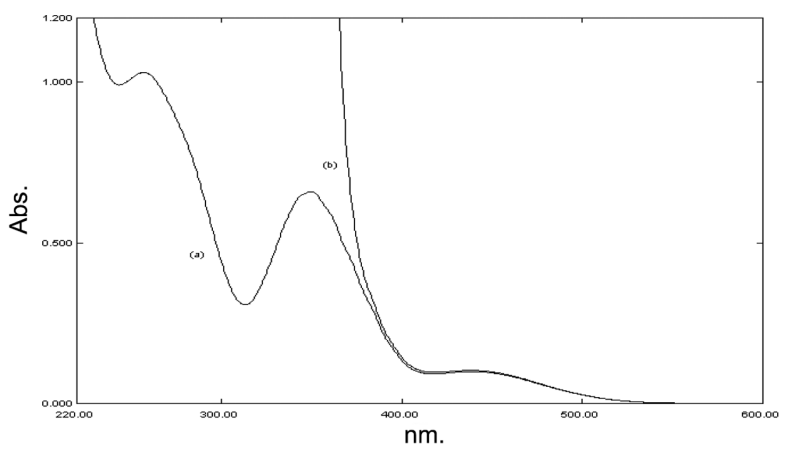

Fig. 6. Absorption spectrum of reaction mixture with and without promoter (in absence of substrate): (A) $[\mathrm{Cr}(\mathrm{VI})]_{\mathrm{T}}=5 \times 10^{-4}$ $\mathrm{mol} \mathrm{dm}{ }^{-3},\left[\mathrm{H}_{2} \mathrm{SO}_{4}\right]_{\mathrm{T}}=0.5 \mathrm{~mol} \mathrm{dm}^{-3}$. (B) $[\mathrm{Cr}(\mathrm{VI})]_{\mathrm{T}}=5 \times 10^{-4} \mathrm{~mol} \mathrm{dm}^{-3}$, $\left[\mathrm{H}_{2} \mathrm{SO}_{4}\right]_{\mathrm{T}}=0.5 \mathrm{~mol} \mathrm{dm}{ }^{-3}$, [phen $]_{\mathrm{T}}=0.01 \mathrm{~mol} \mathrm{dm}^{-3}$.
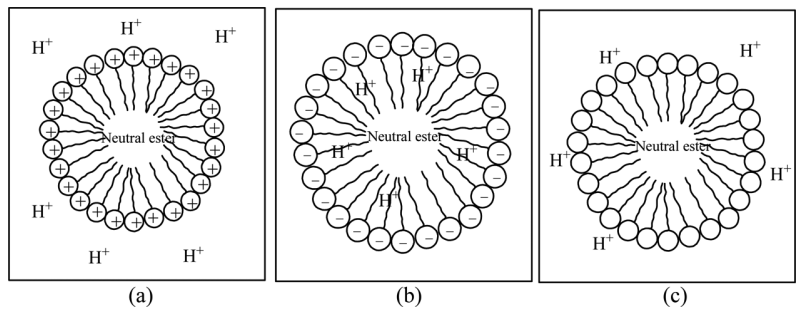

Fig. 7. Schematic representation of partitioning of neutral ester and proton in (a) cationic surfactant (b) Anionic surfactant and (c) Neutral surfactant.

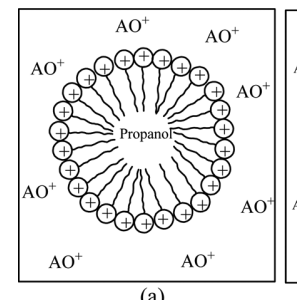

(a)

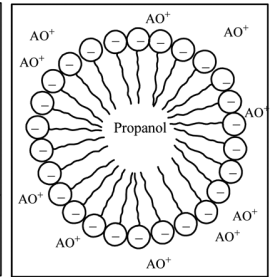

(b)

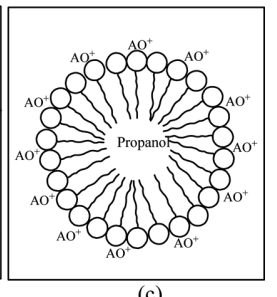

(c)
Fig. 8. Schematic representation of partitioning of substrate and active oxidant $\left[\mathrm{AO}^{+}=\mathrm{Cr}(\mathrm{VI})\right.$-phen complex $]$ in (a) cationic surfactant (b) Anionic surfactant and (C) Neutral surfactant.

to form a ternary complex which experience a redox decomposition in a rate determining step giving rise to organic product. As $\mathrm{Cr}(\mathrm{VI})$-phen is a giant molecule electrostatic attraction is not operating smoothly. For promoted reation rate is maximum in TX-100 followed by SDS (Table 2). Most probably the large hydrophobic core of TX-100 (greater than SDS) allows maximum number of neutral substrate. In case of unpromoted reaction small proton easily penetrated in SDS micelle due to electrostatic attraction, so rate is highest in SDS. But in promoted reaction maximum number of neutral substrate in TX-100 hydrophobic core predominates over electrostatic attraction by positively charged micellar head group of SDS to active oxidant $\mathrm{Cr}(\mathrm{VI})$-phen.
Table 2. Reaction completion time in presence of micellar catalyst and in presence and absence of promoter

\begin{tabular}{|c|c|c|}
\hline \multicolumn{2}{|c|}{ Micellar catalyst $\left[\mathrm{mol} \mathrm{dm}^{-3}\right]$} & $\mathrm{T}_{\text {com }}[\mathrm{hrs}]$ \\
\hline \multicolumn{2}{|c|}{ None } & 1.45 \\
\hline \multirow{4}{*}{ TX-100 } & $2 \times 10^{-2}$ & 0.84 \\
\hline & $3 \times 10^{-2}$ & 0.80 \\
\hline & $4 \times 10^{-2}$ & 0.72 \\
\hline & $5 \times 10^{-2}$ & 0.72 \\
\hline \multirow{4}{*}{ SDS } & $1 \times 10^{-2}$ & 1.59 \\
\hline & $2 \times 10^{-2}$ & 2.36 \\
\hline & $3 \times 10^{-2}$ & 2.83 \\
\hline & $4 \times 10^{-2}$ & 3.06 \\
\hline \multirow{4}{*}{$\mathrm{CPC}$} & $2 \times 10^{-2}$ & 1.79 \\
\hline & $4 \times 10^{-2}$ & 2.54 \\
\hline & $6 \times 10^{-2}$ & 3.42 \\
\hline & $8 \times 10^{-2}$ & 4.26 \\
\hline
\end{tabular}

$[\mathrm{Cr}(\mathrm{VI})]_{\mathrm{T}}=5 \times 10^{-4} \mathrm{~mol} \mathrm{dm}^{-3},\left[\mathrm{H}_{2} \mathrm{SO}_{4}\right]_{\mathrm{T}}=0.5 \mathrm{~mol} \mathrm{dm}^{-3},[\text { propanol }]_{\mathrm{T}}$ $=75 \times 10^{-4} \mathrm{~mol} \mathrm{dm}^{-3},[\mathrm{phen}]_{\mathrm{T}}=50 \times 10^{-4} \mathrm{~mol} \mathrm{dm}^{-3}, \mathrm{Temp}=30^{\circ} \mathrm{C}$.

\section{EXPERIMENTAL}

1, 10-phenanthroline (AR, Merck), propanol (AR, Qualigens), $\mathrm{K}_{2} \mathrm{Cr}_{2} \mathrm{O}_{7}$ (AR, $\mathrm{BDH}$ ), sodium dodecyl sulphate (SDS) (AR, SRL), TX-100 (AR, SRL) and all other chemicals used were of highest degree of purity available commercially. All the solutions were prepared in double distilled water. Solutions of the oxidant and reaction mixtures containing the known quantities of the substrate(s) (i.e. propanol), promoter (1,10-phenanthroline) under the kinetic conditions [propanol $]_{\mathrm{T}}>>[\mathrm{Cr}(\mathrm{VI})]_{\mathrm{T}}$ acid and other necessary chemicals were separately thermostated $\left( \pm 0^{\circ} \mathrm{C}\right)$. The reaction was initiated by the requisite amounts of the oxidant with the reaction mixture. Progress of the reaction is monitored by following the rate of disappearance of $\mathrm{Cr}(\mathrm{VI})$. The concentration of $\mathrm{Cr}(\mathrm{VI})$ at different time intervals was measured by a titrimetric quenching technique using excess of standard Mohr's solution and unreacted Fe(II) was estimated by a standard Ce(IV) solution using ferroin indicator. ${ }^{10 a}$ The pseudo first order rate constants were calculated from the slopes of the plot of $\log [\mathrm{Cr}(\mathrm{VI})]_{\mathrm{t}}$ versus time $t$, which were linear at least for three half lives. The scanned spectra, spectrum after completion of the reaction and other spectra were recorded with a UV-VIS spectrophotometer [UV-1800 and UV-VIS NIR-3600 (SHIMADZU)]. Quartz cuvettes of path length $1 \mathrm{~cm}$ were used. Under the experimental conditions, the possibility of decomposition of the surfactants by $\mathrm{Cr}(\mathrm{VI})$ was investigated and the rate of decomposition in this path was kinetically negligible.

Acknowledgement. Thanks to University of Burdwan and CSIR, New Delhi for offering the opportunity to write 
and for providing financial help in the form of a project and fellowship.

\section{REFERENCES}

1. Pawar, B.; Padalkar,V; Phatangare, K.; Nirmalkar, S.; Chaskar, A. Catal. Sci. Technol. 2011, 1, 1641.

2. Minkler, S. R. K.; Lipshutz, B. H.; Krause, N. Angew. Chem. 2011, 123, 7966.

3. Dwars, T.; Paetzold, E.; Oehme, G. Angew. Chem. 2005, $117,7338$.

4. Nishikata, T.; Lipshutz, B. H. Chem. Commun. 2009, 6472.

5. Saha, R.; Ghosh, A.; Saha, B. J. Coord. Chem. 2011, 64, 3729.

6. Milano-Brusco, J. S.; Nowothnick, H.; Schwarze, M.; Schomacker, R. Ind. Eng. Chem. Res. 2010, 49, 1098.

7. Schwuger, M. J.; Stickdorn, K.; Schomacker, R. Chem. Rev. 1995, 95, 849.

8. M. Gratzel, K. Kalyanasundaram, Eds. Kinetics and Catalysis in Microheterogeneous Systems; Marcel Dekker: New York, 1991.

9. Sudaram, S.; Raghavan, P. S. Chromium-VI reagents: Syn- thetic Application; Springer: 2011.

10. (a) Saha, R.; Nandi, R.; Saha, B. J. Coord. Chem. 2011, 64, 1782. (b) Saha, B.; Orvig, C. Coord. Chem. Rev. 2010, 254, 2959. (c) Meenakshisundaram, S. P.; Gopalkrishnan, M.; Nagarjan, S.; Sarathi, N. Catal. Commun. 2007, 8, 713.

11. (a) Madal, J; Chowdhury, K. M.; Paul, K.; Saha, B. J. Coord. Chem. 2010, 63, 99. (b) Chowdhury, K. M.; Madal, J; Saha, B. J. Coord. Chem. 2009, 62, 1871. (c) Islam, M.; Saha, B.; Das, A.K. J. Mol. Catal A: Chem. 2007, 266, 21. (d) Islam, M.; Saha, B.; Das, A.K. J. Mol. Catal. A: Chem. 2005, 236, 260. (e) Bayen, R.; Islam, M.; Saha, B.; Das, A. K. Carbohydr. Res. 2005, 340, 2163. (f) Meenakshisundaram, S.; Sarathi, N. Trans. Met. Chem. 2006, 31, 369. (g) Meenakshisundaram, S.; Markkandan, R. Trans. Met. Chem. 2004, 29, 308. (h) Khan, Z.; Masan, S.; Ud-Din, Raju, Kabir. Trans. Met. Chem. 2003, 28, 881. (i) Ghosh, S. K.; Basu, A.; Saha, R.; Ghosh, A.; Mukherjee, K.; Saha, B. J. Coord. Chem. (Revised Manuscript has been sent for consideration).

12. Madal, J.; Chowdhury, K. M.; Paul, K. K.; Saha, B. Open Catal. J. 2008, $1,1$. 